\title{
Effects of Physicochemical Factors on Loss of Infectivity of Opisthorchis viverrini Cercariae
}

\author{
Naiyana SENASRI ${ }^{1}$, Smarn TESANA ${ }^{2}$, Chanisala SEREEWONG ${ }^{2}$, \\ Jukkrid CHAIYOS ${ }^{2}$, Monticha CHAIYASAENG ${ }^{2}$ and \\ Sutee WONGMANEEPRATEEP ${ }^{3, *}$
}

${ }^{I}$ Department of Fisheries, Faculty of Natural Resources, Rajamangala University of Technology Isan, Sakon Nakhon Campus, Sakon Nakhon 47160, Thailand

${ }^{2}$ Food-borne Parasite Research Group, Department of Parasitology, Faculty of Medicine, Khon Kaen University, Khon Kaen 40002, Thailand

${ }^{3}$ Department of Fisheries, Faculty of Agriculture, Khon Kaen University, Khon Kaen 40002, Thailand

('Corresponding author's e-mail: suthwo@kku.ac.th)

Received: 4 February 2020, Revised: 7 May 2020, Accepted: 10 June 2020

\begin{abstract}
This study aims to develop an alternative field-based approach to interrupt the life cycle of $O$. viverrini. The effects of temperature, salinity, acidity, ultraviolet $\mathrm{A}, \mathrm{B}, \mathrm{C}$ radiation, and combinations of these physicochemical factors on the loss of infectivity of Opisthorchis viverrini cercariae were analyzed to determine values required for 50 and $95 \%$ lethal concentrations $\left(\mathrm{LC}_{50}\right.$ and $\left.\mathrm{LC}_{95}\right)$ and period of loss infection success $\left(\mathrm{LI}_{50}\right.$ and $\left.\mathrm{LI}_{95}\right)$. Newly shed cercariae of $O$. viverrini were used. $\mathrm{LC}_{50}$ and $\mathrm{LC}_{95}$ values for temperature, salinity, and acidity on cercariae were 33.19 and $37.70{ }^{\circ} \mathrm{C}, 7.29$ and $8.40 \mathrm{ppt}$, 4.62 and 4.80 $\mathrm{M} \mathrm{H}_{2} \mathrm{CO}_{3}$, respectively. The values of $\mathrm{LI}_{50}$ and $\mathrm{LI}_{95}$ on cercariae by exposure to UVA, UVB, and UVC were 19.54 and $20.11 \mathrm{~h}, 5.03$ and $5.12 \mathrm{~h}, 3.37$ and $6.02 \mathrm{~min}$, respectively. Combinations of these factors in the presence of UVC proved damaging to cercariae most rapidly. The shortest loss infection time of $\mathrm{LI}_{50}$ and $\mathrm{LI}_{95}$ were 1.09 and $2.83 \mathrm{~min}$. Cercariae were deemed to have lost the ability to infect cyprinid fish when they had shed their tails, even though they were still capable of some movement. In nature, temperature, salinity, acidity, ultraviolet radiation, and combinations of these factors, affect the ability of $O$. viverrini cercariae to infect cyprinid fish.
\end{abstract}

Keywords: Cercariae, Combinations, Physicochemical factor, Opisthorchis viverrini

\section{Introduction}

Opisthorchis viverrini infection in humans remains a major public health issue in the Greater Mekong Sub-region including Vietnam, Lao PDR, Cambodia, Myanmar, and Thailand [1-4]. In Thailand, 7 million people are infected with this liver fluke, most of them in the northeast of the country. In addition, it has been found that liver fluke is associated with cholangiocarcinoma [2]. Humans acquire the infection by eating raw, fermented, or undercooked cyprinid fish containing the infective stage, mature metacercariae [5]. The parasite life cycle requires the snail Bithynia siamensis goniomphalos as $1^{\text {st }}$ intermediate host in the northeast region of Thailand and many species of cyprinid fishes as $2^{\text {nd }}$ intermediate hosts [6].

In the snail host, germinal cells in sporocysts and rediae multiply by asexual reproduction, ultimately producing many free-swimming cercariae. Numerous cercariae of $O$. viverrini are shed daily from naturally infected snails, with an average of 1,728 cercariae/snail, at the daily peak shedding time of 8:00 - 10:00 a.m. [7]. After finding a cyprinid fish host, cercariae penetrate and encyst to become 
http://wjst.wu.ac.th

metacercariae, mainly in the head portion and muscle [8]. Shed cercariae from snail hosts face changes in temperature [9,10], salinity, acidity [11,12], and UV radiation [13]. These changes could cause the death of cercariae or disable swimming. The number of cercariae that are successful at establishing in fish has important ramifications for infection levels (prevalence and infection intensities) in $2^{\text {nd }}$ intermediate hosts and might influence the survival of these hosts through intensity-dependent mortality [14]. To date, most studies on the survival of cercarial transmission stages have focused on a single environmental factor which allows the investigation of a broader range of factor levels.

This study investigated in vitro of losing infectivity on the effects of physicochemical factors of temperature, salinity, acidity, ultraviolet $\mathrm{A}, \mathrm{B}, \mathrm{C}$ radiation, and combinations of these, on $O$. viverrini cercariae. If these environmental factors can cause loss of infectivity of cercariae, their uses can be incorporated into control programs to assist the eradication of opisthorchiasis in humans.

\section{Materials and methods}

\section{Collection of $O$. viverrini cercariae}

Newly shed cercariae of $O$. viverrini were collected from 9:00 a.m. - 12:00 p.m. from naturally infected B. siamensis goniomphalos. Snails were placed individually in plastic cups $(3 \mathrm{~cm}$ in diameter and $2.5 \mathrm{~cm}$ in height) that contained dechlorinated tap-water. Cercarial shedding was stimulated by exposure to electric light $(40 \mathrm{~W})$ for $2-3 \mathrm{~h}$, after which the water in the cup was examined for the presence of cercariae. Cercariae were morphologically identified as those of $O$. viverrini [6] and confirmed by polymerase chain reaction (PCR) using species-specific primers [15]. Animal use was reviewed and approved by the Institutional Animal Care and Use Committee of Khon Kaen University, based on the Ethics of Animal Experimentation of National Council Research of Thailand (record No. IACUC-KKU$14 / 61)$.

\section{Effects of physicochemical factors on $O$. viverrini cercariae}

Preliminary studies were done for calculation of 50 and $95 \%$ lethal concentrations $\left(\mathrm{LC}_{50}\right.$ and $\left.\mathrm{LC}_{95}\right)$ of water temperature, salinity, and acidity for further study to calculate the period (time) of loss infection success $\left(\mathrm{LI}_{50}\right.$ and $\left.\mathrm{LI}_{95}\right)$. Loss of infection success of cercariae was determined by degeneration of body portions or death or loss of tails. Cercariae which lost their tails could not infect to fish hosts $[16,17]$.

\section{Effects of temperature}

Preliminary study: Cercariae were maintained in a glass box with $3 \mathrm{~mL}$ distilled water (10 cercariae/glass box; 3 replicates for each water temperature) and exposed to water temperature for 30, 31, $32,33,34,35,36$, and $37^{\circ} \mathrm{C}$, and room temperature for the control group, for $24 \mathrm{~h}$. After that, they were examined periodically for a further $24 \mathrm{~h}$, and numbers of cercariae, which had lost their tails, or which had died, were noted. From the data collected, $\mathrm{LC}_{50}$ and $\mathrm{LC}_{95}$ of water temperatures after $24 \mathrm{~h}$ were calculated.

From preliminary studies, $33.19^{\circ} \mathrm{C}$ was determined as the temperature by which $50 \%$ of cercariae had lost infectivity after $24 \mathrm{~h}$. The corresponding value for $95 \%$ loss of infectivity was $37.70{ }^{\circ} \mathrm{C}$. Each group of 30 cercariae (10 cercariae/replicate) was incubated at one of these temperatures (control; room temperature, 33.19 and $37.70^{\circ} \mathrm{C}$ ) for $0,1,3,6,12,24$, and $48 \mathrm{~h}$. Period of loss infection success of cercariae was noted at each time interval; then, the period of loss infection success 50 and $95 \%\left(\mathrm{LI}_{50}\right.$ and $\mathrm{LI}_{95}$ ) values was calculated.

\section{Effects of salinity}

Preliminary study: Cercariae were maintained in a glass box (10 cercariae/glass box; 3 replicates for each concentration) with $3 \mathrm{~mL}$ of $\mathrm{NaCl}$ solutions of the following concentrations: 0 (control), 6.0, 6.5, 7.0, 7.5, 8.0, 8.5 and 9.0 parts per thousand (ppt) for $24 \mathrm{~h}$. After that, they were examined periodically for a further $24 \mathrm{~h}$, and numbers of cercariae, which had lost their tails, or which had died, were noted. From the data collected, concentrations of salinity at which 50 and $95 \%$ of cercariae had a loss of infectivity $\left(\mathrm{LC}_{50}\right.$ and $\left.\mathrm{LC}_{95}\right)$ after $24 \mathrm{~h}$ were calculated. 
http://wjst.wu.ac.th

From preliminary studies, $7.29 \mathrm{ppt}$ was determined as the salinity at which $50 \%$ of cercariae had lost infectivity after $24 \mathrm{~h}$. The corresponding value for $95 \%$ loss of infectivity was 8.40 ppt. Each group of 30 cercariae (10 cercariae/replicate) was incubated at one of these salinities (control; distilled water, 7.29 and $8.40 \mathrm{ppt}$ ) for $0,1,3,6,12,24$, and $48 \mathrm{~h}$. Period of loss infection success of cercariae was noted at each time interval; then, $\mathrm{LI}_{50}$ and $\mathrm{LI}_{95}$ values were calculated.

\section{Effects of acidity}

Preliminary study: Cercariae were maintained in a glass box (10 cercariae/glass box; 3 replicates for each concentration) with $3 \mathrm{~mL}$ of 0 (control; distilled water), 4.40, 4.60, 4.70, 4.80, 4.90, and 5.00 M $\mathrm{H}_{2} \mathrm{CO}_{3}$ for $24 \mathrm{~h}$. After that, they were examined periodically for a further $24 \mathrm{~h}$, and numbers of cercariae, which had lost their tails, or which had died, were noted. From the data collected, concentrations of $\mathrm{H}_{2} \mathrm{CO}_{3}$ at which 50 and $95 \%$ of cercariae had a loss of infectivity $\left(\mathrm{LC}_{50}\right.$ and $\left.\mathrm{LC}_{95}\right)$ after $24 \mathrm{~h}$ were calculated.

From preliminary studies, $4.62 \mathrm{M} \mathrm{H}_{2} \mathrm{CO}_{3}$ was determined as the concentration at which $50 \%$ of cercariae had lost infectivity after $24 \mathrm{~h}$. The corresponding value for $95 \%$ loss of infectivity was $4.80 \mathrm{M}$ $\mathrm{H}_{2} \mathrm{CO}_{3}$. Each group of 30 cercariae (10 cercariae/replicate) was incubated at one of these acidities (control; distilled water, 4.62 and $4.80 \mathrm{M} \mathrm{H}_{2} \mathrm{CO}_{3}$ ) for $0,1,3,6,12,24$, and $48 \mathrm{~h}$. Period of loss infection success of cercariae was noted at each time interval; then, $\mathrm{LI}_{50}$ and $\mathrm{LI}_{95}$ values were calculated.

\section{Effects of ultraviolet A (UVA), B (UVB) and, C (UVC) radiation, $10 \mathrm{~cm}$ from light source Effects of ultraviolet $A$ radiation}

Cercariae were maintained in a glass box (10 cercariae/glass box; 3 replicates for each time interval) with $3 \mathrm{~mL}$ distilled water and constantly exposed to UVA (17,758 lux, FL 15T8/BL, Thai Toshiba Lighting Co., Ltd., Pathumthani, Thailand) for $0 \mathrm{~min}$ (control), 19 h $55 \mathrm{~min}$ (1,195 min), 19 h $57 \mathrm{~min}$ (1,197 min), $19 \mathrm{~h} 59 \mathrm{~min}$ (1,199 $\mathrm{min}), 20 \mathrm{~h} 01 \mathrm{~min}$ (1,201 min), $20 \mathrm{~h} 03 \mathrm{~min}$ (1,203 min) and $20 \mathrm{~h} 05 \mathrm{~min}$ $(1,205 \mathrm{~min})$. After that, they were examined periodically and numbers of cercariae, which had lost their tails, or which had died, were noted. From the data collected, the time of exposure to ultraviolet A radiation by which 50 and $95 \%$ of cercariae had a loss of infectivity $\left(\mathrm{LI}_{50}\right.$ and $\left.\mathrm{LI}_{95}\right)$ was calculated.

\section{Effects of ultraviolet $B$ radiation}

Cercariae were maintained in a glass box (10 cercariae/glass box; 3 replicates for each time interval) with $3 \mathrm{~mL}$ distilled water and constantly exposed to UVB (9,377.59 lux, TL20W/01 RS SLV/25, Philips Lighting Holding B.V, Pila, Poland) for $0 \mathrm{~min}$ (control), $5 \mathrm{~h}$ (300 min), $5 \mathrm{~h} 03 \mathrm{~min}(303 \mathrm{~min}), 5 \mathrm{~h} 05 \mathrm{~min}$ (305 min), 5 h $07 \mathrm{~min}$ (307 $\mathrm{min}), 5 \mathrm{~h} 09 \mathrm{~min}$ (309 min), $5 \mathrm{~h} 11 \mathrm{~min}(311 \mathrm{~min}), 5 \mathrm{~h} 13 \mathrm{~min}(313 \mathrm{~min})$ and $5 \mathrm{~h} 15 \mathrm{~min}(315 \mathrm{~min})$. After that, they were examined periodically and numbers of cercariae, which had lost their tails, or which had died, were noted. From the data collected, the time of exposure to ultraviolet $\mathrm{B}$ radiation at which 50 and $95 \%$ of cercariae had a loss of infectivity $\left(\mathrm{LI}_{50}\right.$ and $\left.\mathrm{LI}_{95}\right)$ was calculated.

\section{Effects of ultraviolet $C$ radiation}

Cercariae were maintained in glass boxes (10 cercariae/glass box; 3 replicates for each time interval) with $3 \mathrm{~mL}$ distilled water and constantly exposed to UVC (3,688.2 lux, UV F17T8, Koninklijke Philips N.V., Eindhoven, Netherlands) for 0 (control), 2, 3, 4, 5, 6 and $7 \mathrm{~min}$. After that, they were examined periodically and numbers of cercariae, which had lost their tails, or which had died, were noted. From the data collected, the time of exposure to ultraviolet $\mathrm{C}$ radiation at which 50 and $95 \%$ of cercariae had a loss of infectivity $\left(\mathrm{LI}_{50}\right.$ and $\left.\mathrm{LI}_{95}\right)$ was calculated.

\section{Combinations of physicochemical factors}

Thirty cercariae (10 cercariae/replicate) were incubated in each combination of conditions for $24 \mathrm{~h}$. Cercariae were exposed to combinations of 2, 3, 4, 5, and 6 factors at the $\mathrm{LC}_{50}$ of water temperature, salinity, and acidity and $\mathrm{LI}_{50}$ of UVA, UVB, and UVC, values for each of those conditions. $\mathrm{LI}_{50}$ values for UV exposure were less than $24 \mathrm{~h}$ in each case. Therefore, in relevant treatments, batches of cercariae were exposed to UV radiation only for the appropriate time, not for the full $24 \mathrm{~h}$. After that, cercariae 
http://wjst.wu.ac.th

were examined. Conditions under which 50 and $95 \%$ of cercariae had lost infectivity $\left(\mathrm{LI}_{50}\right.$ and $\left.\mathrm{LI}_{95}\right)$ were calculated for each combination of factors.

\section{Statistical analysis}

The effects of water temperature, salinity, acidity, ultraviolet A, B, C radiation, and combinations of these, on the survival of cercariae, were evaluated by examination of cercariae under a stereomicroscope. The conditions under which 50 and $95 \%$ of cercariae had lost infectivity or infection time were determined using the probit analysis for each parameter.

\section{Results and discussion}

Effects of physicochemical factors on the loss of infectivity of $O$. viverrini cercariae

Cercariae exhibited abnormal behaviors, abnormal movement, and loss of tails after exposure to various temperatures, salinities, acidities, UVA, UVB, and UVC radiation. Fifty percent and ninety-five percent lethal concentrations $\left(\mathrm{LC}_{50}\right.$ and $\left.\mathrm{LC}_{95}\right)$ were calculated for temperatures, salinities, and acidities of 33.19 and $37.70{ }^{\circ} \mathrm{C}, 7.29$ and $8.40 \mathrm{ppt}, 4.62$ and $4.80 \mathrm{M} \mathrm{H}_{2} \mathrm{CO}_{3}$, respectively. The values of the period of loss infection success 50 and $95 \%\left(\mathrm{LI}_{50}\right.$ and $\left.\mathrm{LI}_{95}\right)$ for ultraviolet $\mathrm{A}, \mathrm{B}$, and $\mathrm{C}$ were 19.54 and $20.11 \mathrm{~h}$, 5.03 and $5.12 \mathrm{~h}, 3.37$ and $6.02 \mathrm{~min}$, respectively (Table 1). At $\mathrm{LC}_{50}$ and $\mathrm{LC}_{95}$ conditions of temperature (33.19 and $37.70{ }^{\circ} \mathrm{C}$, respectively), $\mathrm{LI}_{50}$ and $\mathrm{LI}_{95}$ of cercariae at 6 and $3 \mathrm{~h}$, respectively, were the same as in the control group. After which they sharply decreased to zero at 48 and $24 \mathrm{~h}$, respectively (Figure 1A). Similarly, at $\mathrm{LC}_{50}$ and $\mathrm{LC}_{95}$ values of salinity ( 7.29 and $8.40 \mathrm{ppt}$ ) both groups were the same as controls at 1 and $3 \mathrm{~h}$, after which they sharply decreased to zero at 48 and $24 \mathrm{~h}\left(\mathrm{LC}_{50}\right.$ and $\mathrm{LC}_{95}$, respectively) (Figure 1B). When exposed to $\mathrm{LC}_{50}$ and $\mathrm{LC}_{95}$ levels of acidity (4.62 and $4.80 \mathrm{M} \mathrm{H}_{2} \mathrm{CO}_{3}$ ), cercariae in both groups were the same as controls at 1 and $3 \mathrm{~h}$, after which they sharply decreased to zero at 48 and $24 \mathrm{~h}\left(\mathrm{LC}_{50}\right.$ and $\mathrm{LC}_{95}$ ), respectively (Figure 1C).

\section{Effects of combinations of physicochemical factors on infectivity of $\boldsymbol{O}$. viverrini cercariae}

Cercariae of $O$. viverrini were exposed to combination factors, under the $\mathrm{LI}_{50}$ and $\mathrm{LI}_{95}$ conditions for each. The most effective combination of any 2 factors was acidity and UVC. In order of efficacy from high to low values, were temperature and UVC, salinity and UVC, UVB and UVC, UVA and UVC, acidity and UVB, salinity and UVB, temperature and UVB, temperature and acidity, UVA and UVB, temperature and salinity, salinity and acidity, salinity and UVA, temperature and UVA, and acidity and UVA (Table 2). The most effective combination of 3 factors was salinity, acidity, and UVC. In order of efficacy from high to low values, combinations were temperature, salinity and UVC; temperature, acidity and UVC; UVA, UVB and UVC; salinity, acidity and UVB; temperature, acidity and UVB; temperature, salinity and UVB; temperature, salinity and acidity; temperature, acidity and UVA; salinity, acidity and UVA; and temperature, salinity and UVA (Table 2). The most effective combination of 4 factors was temperature, salinity, acidity and UVC. In order of efficacy from high to low values, combinations were temperature, salinity, acidity and UVB; and temperature, salinity, acidity and UVA (Table 2). The most effective combination of 5 factors was temperature, salinity, acidity, UVA and UVC. In order of efficacy from high to low values, combinations were temperature, salinity, acidity, UVB and UVC, and temperature, salinity, acidity, UVA and UVB (Table 2). The most effective factorial physicochemical factors include temperature, salinity, acidity, UVA, UVB, and UVC (Table 2). 
http://wjst.wu.ac.th

Table 1 The loss of infectivity of $O$. viverrini cercariae exposed to various physicochemical factors.

\begin{tabular}{lcc}
\hline \multirow{2}{*}{ Physicochemical factors } & \multicolumn{2}{c}{ Effects on $\boldsymbol{O}$. viverrini cercariae } \\
\cline { 2 - 3 } & $\mathbf{5 0} \%$ loss of infectivity & $\mathbf{9 5} \%$ loss of infectivity \\
\hline Temperature $\left({ }^{\circ} \mathrm{C}\right)$ & 33.19 & 37.70 \\
Salinity $(\mathrm{ppt})$ & 7.29 & 8.40 \\
Acidity $\left(\mathrm{M} \mathrm{H}_{2} \mathrm{CO}_{3}\right)$ & 4.62 & 4.80 \\
UVA (h) & 19.54 & 20.11 \\
UVB (h) & 5.03 & 5.12 \\
UVC (min) & 3.37 & 6.02 \\
\hline
\end{tabular}

Table 2 Times after which 50 and $95 \%$ of $O$. viverrini cercariae had lost their tails $\left(\mathrm{LI}_{50}\right.$ and $\left.\mathrm{LI}_{95}\right)$ after exposure to combinations of physicochemical factors. Values for each factor were those shown in Table 1.

\begin{tabular}{|c|c|c|}
\hline \multirow{2}{*}{ Combinations of factors } & \multicolumn{2}{|c|}{ Time to loss of tail (min) } \\
\hline & $50 \%$ loss & $95 \%$ loss \\
\hline \multicolumn{3}{|l|}{2 factors } \\
\hline Acidity $\times$ UVC & 1.49 & 4.46 \\
\hline Temperature $\times$ UVC & 1.86 & 6.52 \\
\hline Salinity $\times$ UVC & 2.01 & 4.72 \\
\hline UVB $\times$ UVC & 2.93 & 5.64 \\
\hline $\mathrm{UVA} \times \mathrm{UVC}$ & 3.47 & 6.78 \\
\hline Acidity $\times$ UVB & 60.36 & 240.92 \\
\hline Salinity $\times$ UVB & 120.40 & 240.38 \\
\hline Temperature $\times$ UVB & 120.87 & 300.26 \\
\hline Temperature $\times$ Acidity & 180.48 & 540.45 \\
\hline $\mathrm{UVA} \times \mathrm{UVB}$ & 360.49 & 540.92 \\
\hline Temperature $\times$ Salinity & 480.84 & 840.90 \\
\hline Salinity $\times$ Acidity & 480.92 & 780.22 \\
\hline Salinity $\times$ UVA & 720.24 & 840.56 \\
\hline Temperature $\times$ UVA & 720.50 & 900.48 \\
\hline Acidity $\times$ UVA & 720.88 & 840.99 \\
\hline \multicolumn{3}{|l|}{3 factors } \\
\hline Salinity $\times$ Acidity $\times$ UVC & 1.35 & 3.82 \\
\hline Temperature $\times$ Salinity $\times$ UVC & 1.54 & 5.89 \\
\hline Temperature $\times$ Acidity $\times$ UVC & 1.68 & 4.45 \\
\hline $\mathrm{UVA} \times \mathrm{UVB} \times \mathrm{UVC}$ & 2.92 & 5.59 \\
\hline Salinity $\times$ Acidity $\times$ UVB & 120.25 & 240.56 \\
\hline Temperature $\times$ Acidity $\times$ UVB & 120.35 & 240.14 \\
\hline Temperature $\times$ Salinity $\times$ UVB & 120.65 & 240.92 \\
\hline Temperature $\times$ Salinity $\times$ Acidity & 420.21 & 720.14 \\
\hline Temperature $\times$ Acidity $\times$ UVA & 540.69 & 720.63 \\
\hline Salinity $\times$ Acidity $\times$ UVA & 540.82 & 780.20 \\
\hline Temperature $\times$ Salinity $\times$ UVA & 780.56 & 960.00 \\
\hline \multicolumn{3}{|l|}{4 factors } \\
\hline Temperature $\times$ Salinity $\times$ Acidity $\times$ UVC & 1.34 & 3.84 \\
\hline Temperature $\times$ Salinity $\times$ Acidity $\times$ UVB & 120.72 & 240.43 \\
\hline
\end{tabular}




\begin{tabular}{lcc}
\hline \multirow{2}{*}{ Combinations of factors } & \multicolumn{2}{c}{ Time to loss of tail $(\mathbf{m i n})$} \\
\cline { 2 - 3 } & $\mathbf{5 0} \%$ loss & $\mathbf{9 5 \%}$ loss \\
\hline Temperature $\times$ Salinity $\times$ Acidity $\times$ UVA & 660.79 & 840.95 \\
\hline 5 factors & & \\
\hline Temperature $\times$ Salinity $\times$ Acidity $\times$ UVA $\times$ UVC & 1.44 & 4.67 \\
Temperature $\times$ Salinity $\times$ Acidity $\times$ UVB $\times$ UVC & 1.45 & 4.52 \\
Temperature $\times$ Salinity $\times$ Acidity $\times$ UVA $\times$ UVB & 300.62 & 420.93 \\
\hline 6 factors & & \\
\hline Temperature $\times$ Salinity $\times$ Acidity $\times$ UVA $\times$ UVB $\times$ UVC & 1.09 & 2.83 \\
\hline
\end{tabular}

$\mathbf{A}$

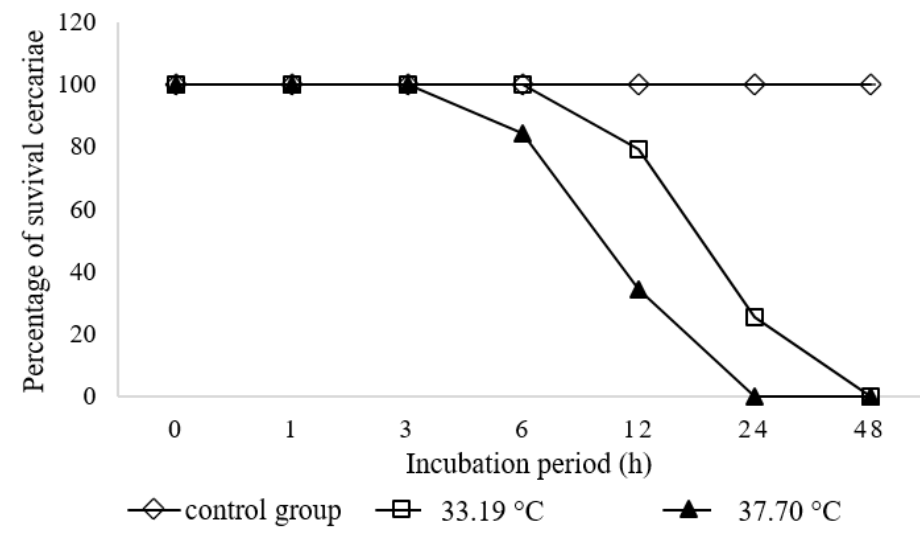

B

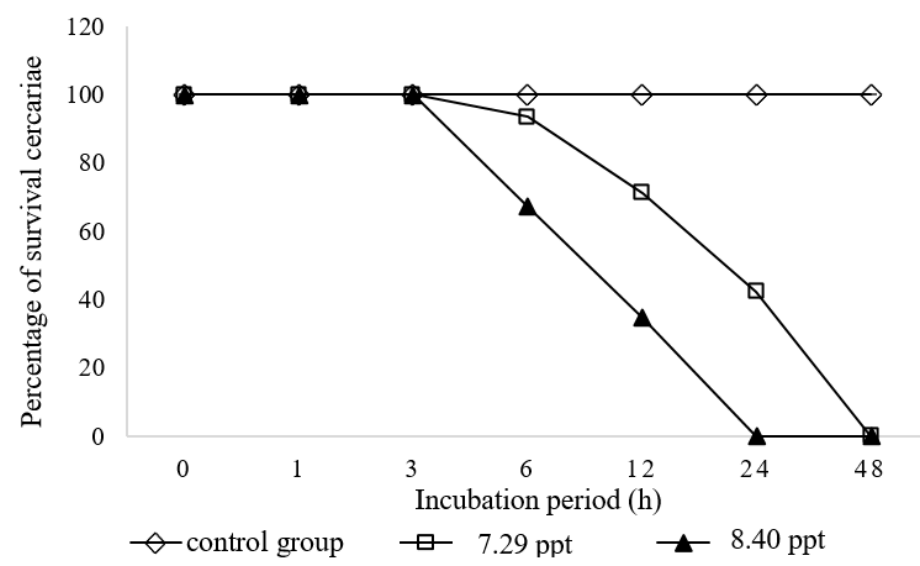


http://wjst.wu.ac.th

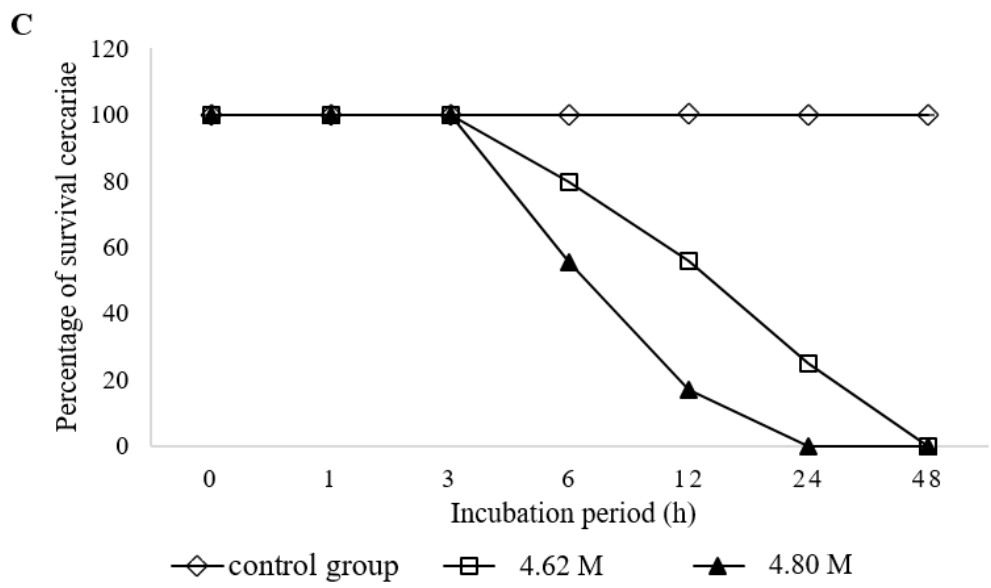

Figure 1 The number of $O$. viverrini cercarial changes at incubation period of temperature (A), salinity (B) and acidity (C).

\section{Discussion}

Climate change is expected to have effects on the distributions of parasitic diseases transmitted via aquatic organisms via alterations in natural temperatures, water levels, salinity, and $\mathrm{pH}$ [18]. They are environmental factors that have been shown to interactively affect the biota of ecosystems. All 4 environmental factors, separately or in combination, were investigated in this experiment and were found to strongly affect the survival of $O$. viverrini cercariae. UVC was the most effective single factor at causing loss of infectivity in fish intermediate hosts. It is not surprising, therefore, that UVC radiation, in combination with all of the other factors, produced the most rapid killing of cercariae $\left(\mathrm{LI}_{50}\right.$ of $1.09 \mathrm{~min}$ and $\mathrm{LI}_{95}$ of $2.83 \mathrm{~min}$ ). Combinations of physicochemical factors accelerate the loss of infectivity of $O$. viverrini cercariae. Similar conclusions were reached previously, in a study of effects of temperature, salinity and UV radiation on the survival of cercariae of an intertidal trematode. Combinations of temperature and UV radiation showed the most deleterious effects on cercariae [19].

Temperature variation is of considerable importance in ecology, as proved to be the case for $O$. viverrini cercariae in our study. Similar conclusions were reported in studies on cercariae of Echinostoma liei (Digenea: Echinostomatidae) [20,21]. In this species, survival steadily decreased with increasing temperature, the maximum survival time falling to approximately $8 \mathrm{~h}$ at $40{ }^{\circ} \mathrm{C}$. The increased mortality at the higher temperature is likely directly linked to increased activity levels, which accelerates the depletion of the finite energy reserves of cercariae [22].

Salinity is a major factor influencing the distribution of aquatic organisms [23], including freshwater snail species, since it affects many of their physiological functions [24,25]. High salinities lead to increased metabolism and physiological malfunction and, at very high levels, mortality [26]. Cercariae of $O$. viverrini lost their infectivity more quickly at the higher salinity levels 7.29 and $8.40 \mathrm{ppt}\left(\mathrm{LC}_{50}\right.$ and $\mathrm{LC}_{95}$, respectively), consistent with findings in a previous study [27]. In that study, snails were exclusively found in water with salinity levels ranging between 0.05 and $22.11 \mathrm{ppt}$ and the highest snail population densities were in rice fields, ponds, roadside ditches, and canals within a water salinity range of 2.5 - 5.0 ppt. The presence of $B$. siamensis goniomphalos was negatively correlated with water salinity. However, it seems that snails can tolerate higher salinities than cercariae of $O$. viverrini.

The mineral acidity of water is a measure of the total acid present [28]. Acidity had detrimental effects on $O$. viverrini cercariae with $\mathrm{LC}_{50}$ and $\mathrm{LC}_{95}$ values of 4.62 and $4.80 \mathrm{M} \mathrm{H}_{2} \mathrm{CO}_{3}$, respectively. The survival of cercariae decreased with increasing acidity. The $\mathrm{pH}$ of the water was generally high but showed greater variations in the pond habitats, which could have an impact on snail populations and distributions. 
http://wjst.wu.ac.th

Ultraviolet radiation is an important environmental factor fluctuating at various spatial and temporal scales and can affect aquatic organisms [29]. We found that to be true in this study. Our observations may thus be more consistent with what has been described for cercariae of Maritrema novaezealandensis [30]. The data presented in ref. [19] consistently confirmed that UV has the potential to impair cercariae and cause disruption of cellular processes and that cercariae of $M$. novaezealandensis possess little, if any, the capacity to prevent and cope with such effects. Ultraviolet light may have several effects on water bodies. In addition to the effect of radiation itself, UV light causes an increase in temperature, which in turn may influence salinity and $\mathrm{pH}$. Cercariae of $O$. viverrini must be influenced by the synergistic effects of all these changes.

\section{Conclusions}

Our study showed temperature, salinity, acidity, ultraviolet A, B, C radiation, and a combination of these factors to affect the ability of $O$. viverrini cercariae to infect cyprinid fish. The development of an alternative field-based approach to interrupt the life cycle of $O$. viverrini by physicochemical of these factors of cercariae could be of value for fish farm management. Fish farms have to the parasite-free, which relieve peoples of anxiousness about opisthorchiasis.

\section{Acknowledgement}

This work was supported by Rajamangala University of Technology Isan, Sakon Nakhon Campus for financial support of this work. We are grateful to our colleagues from the Food-borne Parasite Research Group, Department of Parasitology, Faculty of Medicine, Khon Kaen University, Thailand, for their assistance in fieldwork. Thank you for all the support in this research and sincere thanks to Prof. David Blair for the English language editing.

\section{References}

[1] MR Haswell-Elkins, S Satarug, M Tsuda, E Mairiang, H Esumi, P Sithithaworn, P Mairiang, M Saitoh, P Youngvanit and DB Elkins. Liver fluke infection and cholangiocarcinoma: Model of endogenous nitric oxide and extragastric nitrosation in human carcinogenesis. Mutat. Res. 1994; 305, 241-52.

[2] IARC. Opisthorchis viverrini and Clonorchis sinensis. IARC Monogr. Eval. Carcinog. Risks Hum. 2011; 100b, 347-6.

[3] V Vatanasapt, DM Parkin and S Sriamporn. Epidemiology of Liver Cancer in Thailand. In: V Vatanasapt and B Sripa (Eds.). Liver Cancer in Thailand, Epidemiology, Diagnosis and Control. Siriphan Press, Khon Kaen, Thailand, 2000, p. 3-6.

[4] TH Le, NV De, D Blair, P Sithithaworn and DP McManus. Clonorchis sinensis and Opisthorchis viverrini: Development of a mitochondrial based PCR for their identification and discrimination. Exp. Parasitol. 2006; 112, 109-14.

[5] H Madsen, BT Dung, DT The, NK Viet, A Dalsgaard and PT Van. The role of rice fields, fish ponds and water canals for transmission of fish-borne zoonotic trematodes in aquaculture ponds in Nam Dinh Province, Vietnam. Parasit. Vectors 2015; 8, 625.

[6] DE Wykoff, C Harinasuta, P Juttijudata and MM Winn. Opisthorchis viverrini in Thailand: The life cycle and comparison with O. felineus. J. Parasitol. 1965; 51, 207-14.

[7] P Phongsasakulchoti, P Sri-aroon and Y Kerdpuech. Emergence of Opisthorchis viverrini cercariae from naturally infected Bithynia (Digoniostoma) siamensis goniomphalos. Southeast Asian J. Trop. Med. Public Health 2005; 36, 189-91.

[8] C Donthaisong, P Arunsan, K Suwannatrai, S Prasopdee, J Kulsantiwong, S Wongmaneeprateep, A Suwannatrai and S Tesana. Experimental infection of Opisthorchis viverrini cercariae to the cyprinid fish, Barbonymus gonionotus. Acta Trop. 2014; 136, 118-22.

[9] A Studer, DW Thieltges and R Poulin. Parasites and global warming: Net effects of temperature on an intertidal host-parasite system. Mar. Ecol. Prog. Ser. 2010; 415, 11-22. 
http://wjst.wu.ac.th

[10] DW Thieltges and J Rick. Effect of temperature on emergence, survival and infectivity of cercariae of the marine trematode Renicola roscovita (Digenea: Renicolidae). Dis. Aquat. Organ. 2006; 73, $63-8$.

[11] F Lei and R Poulin. Effects of salinity on multiplication and transmission of an intertidal trematode parasite. Mar. Biol. 2011; 158, 995-1003.

[12] A Studer and R Poulin. Effects of salinity on an intertidal host-parasite system: Is the parasite more sensitive than its host? J. Exp. Mar. Biol. Ecol. 2012; 412, 110-6.

[13] A Studer and R Poulin. Seasonal dynamics in an intertidal mudflat: The case of a complex trematode life cycle. Mar. Ecol. Progr. Ser. 2012; 455, 79-93.

[14] B Fredensborg, KN Mouritsen and R Poulin. Intensity-dependent mortality of Paracalliope novizealandiae (Amphipoda: Crustacea) infected by a trematode: Experimental infections and field observations. J. Exp. Mar. Biol. Ecol. 2004; 311, 253-65.

[15] S Wongratanacheewin, W Pumidonming, RW Sermswan and W Maleewong. Development of a PCR-based method for the detection of Opisthorchis viverrini in experimentally infected hamsters. Parasitology 2001; 122, 175-80.

[16] NJ Morley, M Crane and JW Lewis. Toxicity of cadmium and zinc to cercarial tail loss in Diplostomum spathaceum (Trematoda: Diplostomidae). Parasitology 2002; 125, 293-301.

[17] JN Stables and LH Chappell. Diplostomum spathaceum (Rud. 1819): Effects of physical factors on the infection of rainbow trout (Salmo gairdneri) by cercariae. Parasitology 1986; 93, 71-9.

[18] DJ Marcogliese. Implications of climate change for parasitism of animals in the aquatic environment. Can. J. Zool. 2001; 79, 1331-52.

[19] A Studer and R Poulin. Cercarial survival in an intertidal trematode: A multifactorial experiment with temperature, salinity and ultraviolet radiation. Parasitol. Res. 2013; 112, 243-9.

[20] NA Evans. The influence of environmental temperature upon transmission of the cercariae of Echinostoma liei (Digenea: Echinostomatidae). Parasitology 1985; 90, $269-75$.

[21] AM McCarthy. The influence of temperature on the survival and infectivity of the cercariae of Echinoparyphium recurvatum (Digenea: Echinostomatidae). Parasitology 1999; 118, 383-8.

[22] JA Pechenik and B Fried. Effect of temperature on survival and infectivity of Echinostoma trivolvis cercariae: A test of the energy limitation hypothesis. Parasitology 1995; 111, 373-8.

[23] A Remane and C Schlieper. Biology of Brackish Water. Vol XXV. Wiley Interscience Division, John Wiley \& Sons, New York, 1971.

[24] LF Gainey Jr and MJ Greenberg. Physiological basis of the species abundance-salinity relationship in molluscs: A speculation. Mar. Biol. 1977; 40, 41-9.

[25] R Lindahl-Jacobsen and VE Forbes. Clonal variation in life-history traits and feeding rates in the gastropod, Potamopyrgus antipodarum: Performance across a salinity gradient. Funct. Ecol. 1997; 11, 260-7.

[26] SG Cheung and SW Lam. Effect of salinity, temperature and acclimation on oxygen consumption of Nassarius festivus (Powys, 1835) (Gastropoda: Nassariidae). Comp. Biochem. Physiol. 1995; 111, 625-31.

[27] A Suwannatrai, K Suwannatrai, S Haruay, S Piratae, C Thammasiri, P Khampoosa, J Kulsantiwong, S Prasopdee, P Tarbsripair, R Suwanwerakamtorn, S Sukchan, T Boonmars, JB Malone, MT Kearney and S Tesana. Effect of soil surface salt on the density and distribution of the snail Bithynia siamensis goniomphalos in northeast Thailand. Geospat. Health 2011; 5, 183-90.

[28] CE Boyd. Water quality for pond aquaculture. Research and Development Series No. 43. International Center for Aquaculture and Aquatic Environments, Alabama Agricultural Experiment Station, Auburn University, 1998.

[29] LA Hansson and S Hylander. Effects of ultraviolet radiation on pigmentation, photoenzymaticrepair, behavior, and community ecology of zooplankton. Photochem. Photobiol. Sci. 2009; 8, 1266-75.

[30] A Studer, VM Cubillos, MD Lamare, R Poulin and DJ Burritt. Effects of ultraviolet radiation on an intertidal trematode parasite: An assessment of damage and protection. Int. J. Parasitol. 2012; 42, 453-61. 